\title{
(6) OPEN ACCESS \\ Sustained health-economic effects after reorganisation of a Swiss hospital emergency centre: a cost comparison study
}

\author{
Klaus Eichler, ${ }_{1}$ Sascha Hess, ${ }^{1}$ Corinne Chmiel ${ }_{1}^{2,3}$ Karin Böglii, ${ }^{2}$ Patrick Sidler, ${ }^{2}$ \\ Oliver Senn, ${ }^{3}$ Thomas Rosemann, ${ }^{3}$ Urs Brügger ${ }^{1}$
}

\begin{abstract}
${ }^{1}$ Winterthur Institute of Health Economics, Zurich University of Applied Sciences, Winterthur, Switzerland

${ }^{2}$ City Hospital Waid, Zurich, Switzerland

${ }^{3}$ Institute of General Practice and Health Services Research, University of Zurich, Zurich, Switzerland
\end{abstract}

\section{Correspondence to} Dr Klaus Eichler, Winterthur Institute of Health Economics, Zurich University of Applied Sciences, Gertrudstrasse 15, P.O. Box, Winterthur CH 8401, Switzerland; eich@zhaw.ch

Received 22 April 2013 Accepted 17 June 2013 Published Online First 12 July 2013

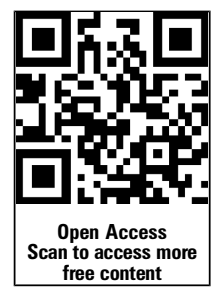

CrossMark

To cite: Eichler $\mathrm{K}$, Hess $\mathrm{S}$, Chmiel C, et al. Emerg Med J 2014;31:818-823.

\begin{abstract}
Background Emergency departments (EDs) are increasingly overcrowded by walk-in patients. However, little is known about health-economic consequences resulting from long waiting times and inefficient use of specialised resources. We have evaluated a quality improvement project of a Swiss urban hospital: In 2009, a triage system and a hospital-associated primary care unit with General Practitioners (H-GP-unit) were implemented beside the conventional hospital ED. This resulted in improved medical service provision with reduced process times and more efficient diagnostic testing. We now report on health-economic effects.

Methods From the hospital perspective, we performed a cost comparison study analysing treatment costs in the old emergency model (ED, only) versus treatment costs in the new emergency model (triage plus ED plus H-GP-unit) from 2007 to 2011. Hospital cost accounting data were applied. All consecutive outpatient emergency contacts were included for 1 month in each follow-up year. Results The annual number of outpatient emergency contacts increased from $n=10440$ (2007; baseline) to $n=16326$ (2011; after intervention), reflecting a general trend. In 2007, mean treatment costs per outpatient were $€ 358$ (95\% Cl 342 to 375$)$. Until 2011, costs increased in the $E D(€ 423$ (396 to 454)), but considerably decreased in the H-GP-unit (€235 (221 to 250)). Compared with 2007, the annual local budget spent for treatment of 16326 patients in 2011 showed cost reductions of $€ 417600$ (27 200 to 493600 ) after adjustment for increasing patient numbers.
\end{abstract}

Conclusions From the health-economic point of view, our new service model shows 'dominance' over the old model: While quality of service provision improved (reduced waiting times; more efficient resource use in the H-GP-unit), treatment costs sustainably decreased against the secular trend of increase.

\section{BACKGROUND}

Capacity overload of hospital emergency units is a common problem. ${ }^{1}$ Examples can be found in Germany, Belgium, Canada ${ }^{2}$ or the USA. ${ }^{3}$ Also in Switzerland emergency departments (EDs) are increasingly overcrowded by walk-in patients. This may result in low quality care with long waiting times and inefficient use of specialised services. ${ }^{4}$ Furthermore, this may impede patient safety ${ }^{5}$ and result in increased treatment costs.

Several successful projects have been launched to improve emergency services, for example by implementing triage systems or involving general practitioners (GPs) from the community in the treatment of walk-in patients with less urgent health problems. ${ }^{6}$

Little data, however, have been published about health-economic effects of such ED quality improvement projects. ${ }^{4}$ With this paper, we report the final health-economic results of our evaluation of an urban hospital emergency service in Switzerland, where a redesign of the patient flow process was implemented to improve service provision for emergency outpatients.

\section{METHODS}

We used a before-after design and performed a cost comparison study with prospective data collection. ${ }^{7}$ The results of our project concerning indicators for medical service quality and staff satisfaction have been reported elsewhere. ${ }^{89}$ Briefly, patient satisfaction was measured with a validated questionnaire that covered established dimensions of patient needs in emergency care. Patient satisfaction was high at baseline and showed no relevant change during follow-up in the ED and the hospital-associated primary care unit with GPs (H-GP-unit), as well. Over $95 \%$ of responding patients reported (complete or reasonable) 'trust in the correctness of diagnosis' and that 'all necessary examinations had been done'. Job satisfaction data of ED staff, as well as of GPs in the H-GP-unit were anonymously collected with a questionnaire (response rate 72-88\%). Overall job satisfaction of ED staff (visual analogue scale, VAS, 0-100) improved from 76.5 points (baseline) to 82.4 points (6 months) and 83.9 points ( 2 years). The difference between baseline and 2 years follow-up was 7.4 points $(95 \%$ CI 1.3 to 13.5; standardised effect size: 0.85 , ie, moderate to strong effect). ${ }^{9}$ The most improved dimensions of job satisfaction were 'addressing individual needs of patients', 'personal work load', 'influence of work on physical health' and 'influence of work on mental health'. The majority of the GPs preferred doing their out-of-hours service within the new H-PG-unit.

\section{Setting}

The quality improvement project was conducted in the emergency service of a municipal hospital in Switzerland (Stadtspital Waid; Zurich; catchment population 180000 people). In Switzerland, patients with emergent medical problems have free access to one of the following emergency services ${ }^{10}$ : (1) GP of their own; (2) Emergency Medical Service 
Telephone, which connects the patient after a triage with the suitable service (during night time, eg, with an out-of-hour GP on duty $^{11}{ }^{12}$ ) (3) some few urban walk-in emergency centres; or (4) a hospital emergency centre. In Switzerland, healthcare insurance is part of the social insurance system and mandatory for all citizens. For the outpatient sector, as covered by our study, health insurance companies have to reimburse the charges of emergency service providers in addition to a mandatory variable deductible depending on the insurance model chosen by the patient.

\section{Problem and intervention}

In 2007, a baseline measurement was performed with involvement of staff during planning and data collection. This measurement before intervention showed 54\% self-referred patients (79\% of them treated by ambulatory care), long waiting times and substantial treatment costs among outpatients treated with specialised emergency services. ${ }^{10}$

The hospital owner decided for an organisational intervention according to the Cochrane Effective Practice and Organisation of Care (EPOC)-Group. ${ }^{13}$ The change strategy focused on structure of care (redesign of the patient flow process), as well as on provider oriented issues (building of a new clinical multidisciplinary team; formal integration of services; improvement of staff satisfaction). In the new model, a triage system and a hospital-associated primary care unit with GPs (H-GP-unit as a 'fast track' ${ }^{1}$ ) were implemented beside the conventional hospital ED (figure 1). As the first point-of-care trained nurses estimated the Emergency Severity Index (ESI), a score ranging from 1 'life threatening' to 5 'least severe'. ${ }^{14}$ Subsequently, patients were directed to the appropriate service unit according to urgency and expected service needs (ie, patients with ESI score 1-3 to the ED; patients with ESI score 4 or 5 (no immediate life-saving intervention and no or only one resource needed, such as lab test) to the H-GP-unit). Depending on the capacity of the H-GP-unit, patients with ESI 4 or 5 were also directed to the ED. Hospital staff, GPs and emergency patients were involved in the quality improvement project. A hospital-based action team (comprising hospital management, staff of the ED and GPs) took responsibility for change and was in charge of team building, project coordination and communication within the hospital and the community (eg, via quality boards; newsletters; press releases).

\section{Comparison of alternatives}

We compared treatment costs in the old emergency model (ED, only) versus treatment costs in the new emergency model (triage plus ED plus H-GP-unit).

\section{Subjects and data collection}

All consecutive outpatient emergency contacts were included for measurement for 1 month in each follow-up year $(2007 ; 2009$; 2010; 2011). Baseline measurement took place in October 2007. The new structures were implemented in March 2009 with follow-up measurements in August 2009 (6 months), April 2010 (year 1) and April 2011 (year 2) to allow an identification of sustained effects and taking seasonal variability into account. Data from repeated measurements were also necessary for an efficient plan-do-check-act approach during the project. Using a validated outcome tool, information on patient variables (age, gender) was collected. ${ }^{8}$ Medical problems were coded in randomly selected patients according to ICPC-2 (International Classification of Primary Care). ${ }^{15}$

Costs were derived from hospital cost accounting data where costs per patient are calculated according to Swiss cantonal standard procedures for hospital cost accounting. ${ }^{16}$ Labour costs were derived by prospectively documented nursing time units multiplied by current nursing wages. Physician time units were allocated to each patient relative to nursing time and multiplied by current physician wages. Material costs were derived by counting units of applied diagnostic tests or medications multiplied by current Swiss prices. Some additional cost elements (eg, for administration) were allocated as a fixed rate to each patient. Interest and capital costs were not included in our analysis as reliable assignment of such costs to the outpatient service system is hardly possible in Switzerland due to inconsistent accounting over the last few years.

\section{Pricing and perspective of economic evaluation}

We present 2007-2011 treatment costs in Euros, $€$ (after conversion from Swiss Francs, SFr, by factor 0.8 ). We choose the perspective of the municipal hospital, as the quality improvement project was initiated by the hospital management. Thus, our results should primarily inform decision makers within the hospital and local authorities about the costs of service provision. For our analysis, we did not rely on hospital billing data for
Figure 1 Old model (2007) and new model (since 2009) of the emergency service at Stadtspital Waid, Zurich.
Baseline data: 2007

Follow-up: 2011

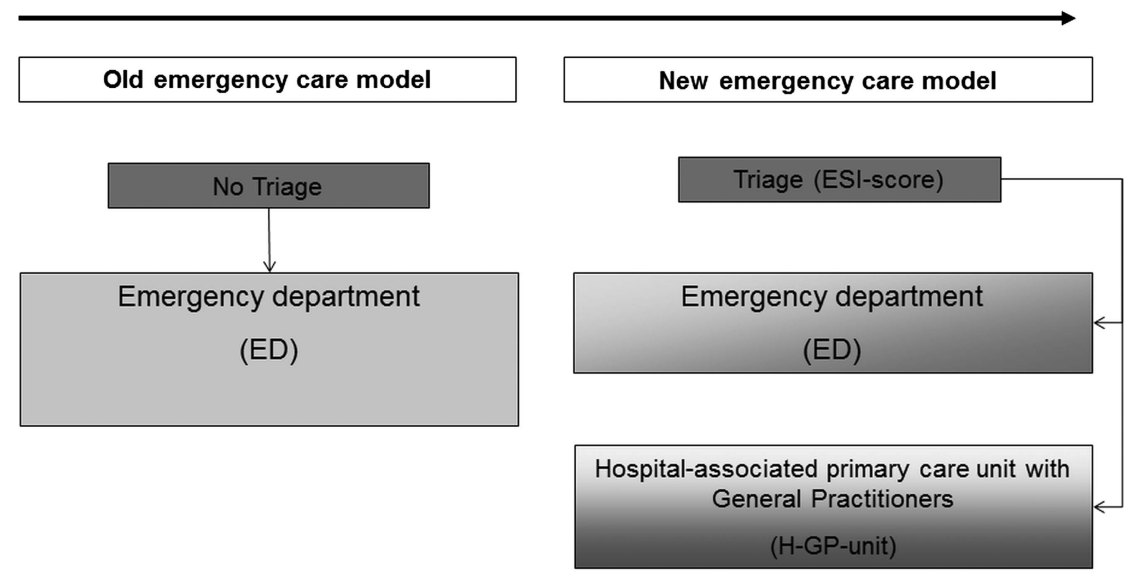


healthcare insurances. In Switzerland, billing data are based on tariffs, reflect the result of negotiations between providers and healthcare insurances and are administrative prices. Current standards for performing health-economic evaluations were applied. $^{7}$

\section{Statistical analysis}

For our descriptive analysis, we used means (SD) or medians (IQR) for continuous variables and proportions for categorical data. For inferential analysis of cost data, we calculated $95 \%-\mathrm{CIs}^{17}$ using the non-parametric bootstrap. ${ }^{18}$ To account for confounding variables we applied multivariable linear regression. Costs were not discounted due to the short time frame.

To assess the economic impact of the quality improvement project on costs of the emergency service, we used a stepwise approach: First, treatment costs per patient in the ED and H-GP-unit were calculated for each assessment year. In addition, we calculated treatment costs for different ESI-triage classes and specific clusters of diagnoses according to ICPC-2 data. Second, treatment costs per year for the hospital were calculated as the sum of costs in the ED (ie, average costs per ED-patient multiplied by the annual number of outpatients treated in the ED) plus costs in the H-GP-unit (ie, average costs per H-GP-patient multiplied by the annual number of outpatients treated in the H-GP-unit). Then we compared the old model with the new model, that is, we compared the total annual local budget spent to treat emergency outpatients in 2007 (baseline) with that of 2011 (last follow-up year) accounting for different patient numbers. Data analysis was conducted with SPSS for Windows, V.18.0 (SPSS Inc., Chicago, Illinois, USA).

\section{RESULTS}

\section{Patients and medical problems}

The annual number of outpatient emergency contacts in the study hospital increased from $n=10440$ (2007; baseline) to $n=16326$ (2011), reflecting a general trend. ED overcrowding was substantially mitigated against this general trend. In 2011, $52 \%(n=8478)$ of emergency outpatients were treated in the ED and $48 \%(n=7848)$ in the H-GP-unit. Thus, the annual number of outpatient contacts in the ED could be reduced by $19 \%$.

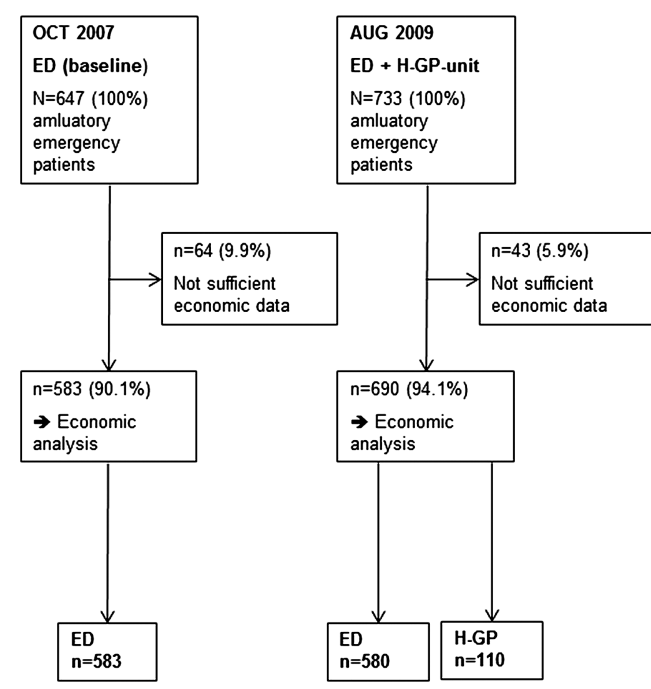

Within the four measurement periods, 3155 emergency patients were treated by outpatient services (figure 2). Of those, 2901 patients (between $90.1 \%$ and $94.2 \%$ per period) showed sufficient economic data for final analysis (ED: $n=1761$; H-GP-unit: $n=1140$ ). The proportion of men was lower among ED patients (range: 44-45\%) compared with H-GP-patients (range: 47-56\%; table 1). Patients treated in the H-GP-Unit were slightly younger (range of median age: 33-37 years) compared with the ED (range: $39-40$ years). Distribution of medical problems (according to ICPC-chapter) showed similar patterns in the ED and the H-GP-unit, with musculoskeletal problems $(30-36 \%)$ and skin related problems $(20-28 \%)$ as the most common groups. Retriage rate from the H-GP-unit to the ED was persistently low with less than $3 \%$.

\section{Cost data}

\section{Treatment costs per patient}

In 2007, mean treatment cost $(95 \% \mathrm{CI})$ per outpatient were $€ 358$ ( $€ 342$ to $€ 375$ ). After implementation of the H-GP-unit mean treatment costs $(95 \% \mathrm{CI})$ for patients in the H-GP decreased from $€ 250$ ( $€ 232$ to $€ 274$ ) in 2009 to $€ 218$ (€209 to $€ 230)$ in 2010 and $€ 235$ (€221 to $€ 250)$ in 2011 (figure 3). This was mainly due to reduction in material costs (eg, diagnostic testing) and to some extent due to reduced labour costs.

As expected due to some shift in the patient mix after triage, mean treatment cost $(95 \% \mathrm{CI})$ for patients in the traditional ED showed an increase from $€ 358$ (baseline) to $€ 429$ (€406 to $€ 454)$ in 2009 and $€ 423$ (€396 to $€ 454)$ in 2011. This was mainly due to an increase in labour costs, while material costs showed only a minor increase compared with the old model.

Depending on the capacity of the H-GP-unit, the ED continued to treat lower urgency classes. The difference in treatment costs between the two service tracks in the new model was also evident within the same ESI-classes. Direct comparison of these patients in 2011 showed significantly lower mean costs $(95 \%$ $\mathrm{CI}$ ) in the H-GP-unit for ESI 4 patients (H-GP: $€ 249$ (€230 to $€ 271)$; ED: $€ 384$ (€353 to $€ 416)$ ) as well as for ESI 5 patients (H-GP: $€ 182$ (€170 to $€ 195)$; ED: $€ 315$ (€234 to $€ 418)$ ). This difference remained basically unchanged after adjustment for age and sex imbalances between treatment units.

Treatment costs for clusters of frequent diagnoses in each of the service tracks are shown in table 2. Treatment costs in the

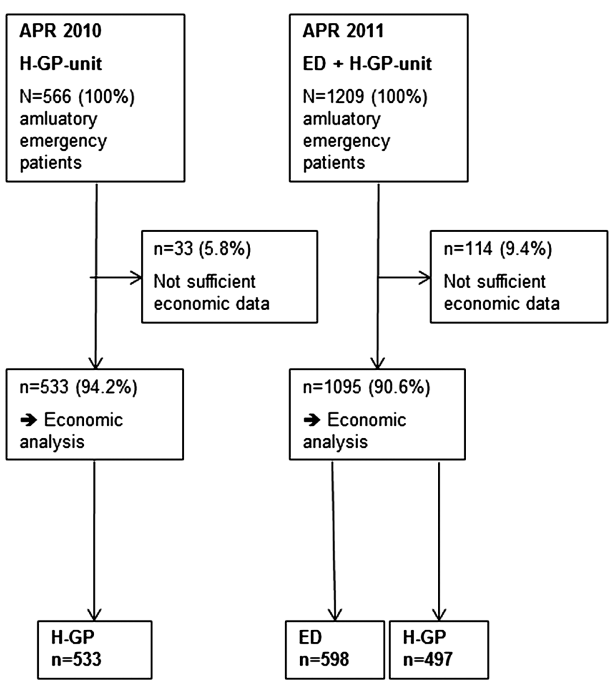

Figure 2 Study flow. 
Table 1 Patients and frequency of common medical problems. Patients with complete economic data are included

\begin{tabular}{|c|c|c|c|c|c|c|c|}
\hline & $\begin{array}{l}\text { OCT } 2007 \\
\text { ED } \\
\mathrm{N}=583\end{array}$ & $\begin{array}{l}\text { AUG } 2009 \text { ED } \\
\mathrm{N}=580\end{array}$ & $\begin{array}{l}\text { AUG } 2009 \\
\text { H-GP } \\
\mathrm{N}=110\end{array}$ & $\begin{array}{l}\text { APR } 2010 \text { ED } \\
\text { No measurement } \\
\text { cycle }\end{array}$ & $\begin{array}{l}\text { APR } 2010 \\
\text { H-GP } \\
\mathrm{N}=533\end{array}$ & $\begin{array}{l}\text { APR } 2011 \text { ED } \\
\mathrm{N}=598\end{array}$ & $\begin{array}{l}\text { APR } 2011 \\
\text { H-GP } \\
\mathrm{N}=497\end{array}$ \\
\hline Gender* & $\mathrm{n}=583$ & $\mathrm{n}=580$ & $\mathrm{n}=110$ & - & $\mathrm{n}=533$ & $\mathrm{n}=597$ & $\mathrm{n}=497$ \\
\hline Men, No. (\%) & $261(44.8)$ & $256(44.1)$ & $62(56.4)$ & - & $281(52.7)$ & $270(45.2)$ & $233(46.9)$ \\
\hline Age $^{*}$ & $\mathrm{n}=583$ & $\mathrm{n}=580$ & $\mathrm{n}=110$ & - & $\mathrm{n}=533$ & $\mathrm{n}=596$ & $\mathrm{n}=494$ \\
\hline Years, median (IQRt) & $39(26-56)$ & $39(28-56)$ & $33(23-48)$ & - & $37(26-51)$ & $40(26-58)$ & $35(21-51)$ \\
\hline Medical problems* $\ddagger$ & $n=127 \S$ & $\begin{array}{l}\text { No measurement } \\
\text { cycle }\end{array}$ & $\mathrm{n}=107$ & $\begin{array}{l}\text { No measurement } \\
\text { cycle }\end{array}$ & $n=531$ & $\begin{array}{l}\text { No measurement } \\
\text { cycle }\end{array}$ & $\mathrm{n}=491$ \\
\hline Digestive (D), No. (\%) & 16 (12.6) & - & $9(8.4)$ & - & $41(7.7)$ & - & $56(11.4)$ \\
\hline Musculoskeletal (L), No. (\%) & $37(29.1)$ & - & $39(36.4)$ & - & $164(30.9)$ & - & $145(29.5)$ \\
\hline Respiratory (R), No. (\%) & $9(7.1)$ & - & $9(8.4)$ & - & 99 (18.6) & - & $57(11.6)$ \\
\hline Skin (S), No. (\%) & 35 (27.6) & - & $29(27.1)$ & - & $108(20.3)$ & - & $126(25.7)$ \\
\hline
\end{tabular}

H-GP-unit are lower for patients with upper respiratory tract infections and injury related diagnoses of the hand, foot or skin, while no apparent difference shows for patients with neck/back syndrome. This comparison, however, has to be viewed with caution due to a small sample size and lack of ICPC-data from the ED during follow-up.

Annual local budget for treatment of emergency patients

The annual number of outpatient emergency contacts to be treated by our hospital increased from year to year, reflecting a general trend. While the study hospital served $n=10440$ patients with the old ED-model in 2007, $n=16326$ contacts (ED: $n=8478$; H-GP-unit: $n=7848$ ) were counted in 2011 . Applying the April 2011 cost data (mean costs per patient ED: $€ 423$; H-GP-unit: $€ 235$ ) to this 2011 service pattern, the annual local budget spent by the study hospital for treatment of 16326 patients in 2011 was $€ 5433600$.

If the same number of 16326 patients had been treated in 2011 with the old structures (2007: ED only; mean costs: $€ 358$ ), the annual local budget spent by the study hospital for treatment of emergency patients would have amounted to $€ 5851200$. Thus, relying on these assumptions, annual cost reductions $(95 \% \mathrm{CI})$ for the local budget of $€ 417600$ (€27 200 to $€ 493600$ ) resulted in 2011 . This comparison is a conservative estimate, as the increase in wages and material prices from 2007 to 2011 is not accounted for.

\section{DISCUSSION}

Our implementation of patient triage and a fast track (organisational intervention) in combination with cultural measures (hospital-based action team; involvement of several groups of health professionals) led to decreased treatment costs of emergency outpatients in the newly installed H-GP-unit. A comparison with treatment costs in the previous service suggests, that our intervention led to a reduced annual local budget required for treatment of an increasing number of emergency outpatients in 2011 of approximately $€ 415000$. One might argue that the triage system segregated two different patient populations with different service needs. However, only outpatients were included and the cost difference between the two service units also holds for patients within the same severity index class and adjusted for confounding factors.

These economic consequences are due to improvements in service provision, as reported elsewhere: Median process time from admission to discharge of patients was reduced by $50 \%$ (ED: $120 \mathrm{~min}$; H-GP-unit: $60 \mathrm{~min}$ ), as well as frequency of additional diagnostic testing (share of patients with additional

Figure 3 Costs of emergency care for outpatients according to treatment unit. Only outpatients were included in our study. Mean costs are displayed in Euro $(€)$ for the emergency department (ED: black squares) and the hospital General Practitioner-unit (H-GP: black circles). Error bars indicate $95 \% \mathrm{Cls}$ of mean costs.

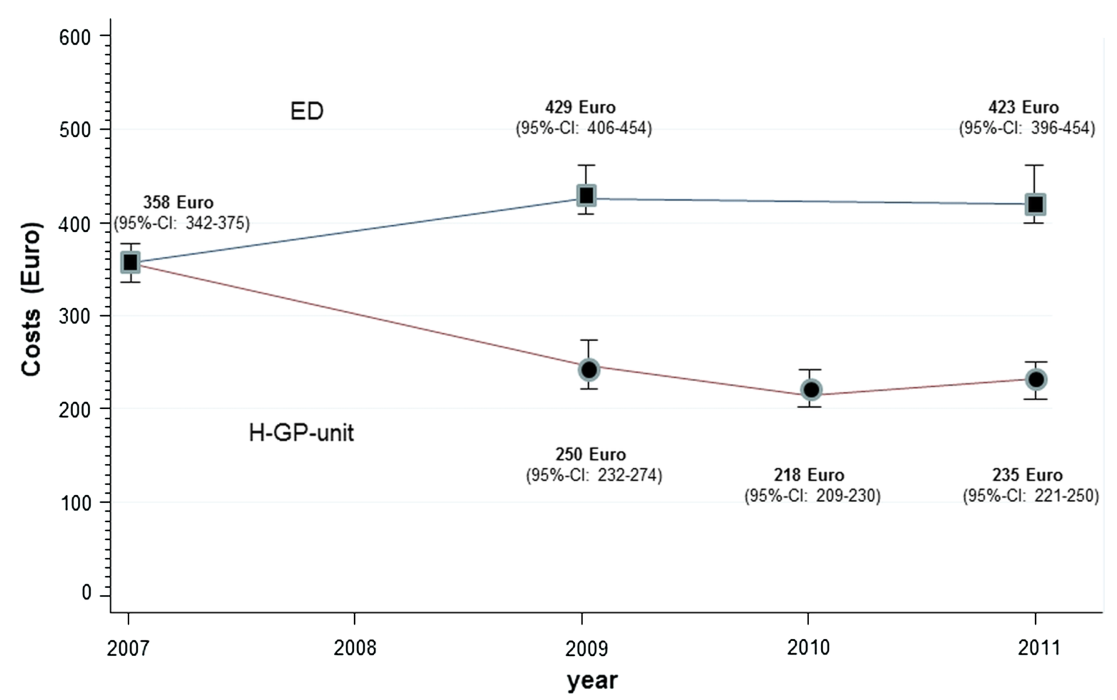


Table 2 Treatment costs for clusters of frequent diagnoses. Patients with ICPC-2 information and complete economic data are included

\begin{tabular}{|c|c|c|c|c|}
\hline & $\begin{array}{l}\text { OCT } 2007 \\
\text { ED } \\
N=127\end{array}$ & $\begin{array}{l}\text { AUG } 2009 \\
\text { H-GP } \\
\mathrm{N}=107\end{array}$ & $\begin{array}{l}\text { APR } 2010 \\
\text { H-GP } \\
\mathrm{N}=531\end{array}$ & $\begin{array}{l}\text { APR } 2011 \\
\text { H-GP } \\
\mathrm{N}=491\end{array}$ \\
\hline Neck/back syndrome* & $n=7$ & $n=12$ & $n=43$ & $n=39$ \\
\hline Costs, $€$, Mean (SD) & $223(52)$ & $242(107)$ & $185(81)$ & $221(186)$ \\
\hline $\begin{array}{l}\text { Upper respiratory tract } \\
\text { infectiont }\end{array}$ & $n=2$ & $n=6$ & $n=68$ & $n=36$ \\
\hline Costs, $€$, Mean (SD) & $388(18)$ & $289(85)$ & $189(62)$ & $192(48)$ \\
\hline Fracture sprain hand footł & $n=23$ & $n=19$ & $n=53$ & $n=61$ \\
\hline Costs, $€$, Mean (SD) & $355(102)$ & 270 (129) & $264(125)$ & $280(216)$ \\
\hline Skin injury§ & $n=25$ & $n=21$ & $n=63$ & $n=65$ \\
\hline Costs, $€$, Mean (SD) & $318(93)$ & $215(90)$ & $238(113)$ & $284(241)$ \\
\hline \multicolumn{5}{|c|}{$\begin{array}{l}\text { *Neck back syndrome includes ICPC-2 codes L83; L84; L86. } \\
\text { tUpper respiratory tract infection includes ICPC-2 codes R74; R75; R76; R77; R78; } \\
\text { R80. } \\
\text { †Fracture sprain hand foot includes ICPC-2 codes L74, L76, L77, L78, L79. } \\
\text { §Skin injury includes ICPC-2 codes S16, S18. } \\
\text { ED, emergency department; H-GP; hospital General Practitioner. }\end{array}$} \\
\hline
\end{tabular}

diagnostic testing: ED 71\%; H-GP 56\%). ${ }^{8}$ In addition, patient satisfaction persisted at a high levels ${ }^{8}$ and staff satisfaction in the ED rose significantly. ${ }^{9}$

\section{Strengths and limitations of our approach}

Our evaluation provides real world data of a prospectively planned evaluation in an area of relevance for patient-oriented health services. We combined data of service provision and economic consequences to improve the health-economic knowledge base for health services research.

Some limitations have to be mentioned: First, we did not measure clinical outcomes. This was not possible due to staff time and budget constraints. We suggest that our low retriage rate is an indicator for suitable decision-making to get the right patients to the right service. Second, data for medical problems of ED patients were not available for follow-up. The pattern of common medical problems treated in the H-GP-unit, however, was similar compared with the ED at baseline. This suggests that the overall mix of emergency outpatients in our hospital did not change over time. Third, interest and capital costs were not included in our analysis. We don't believe that this has a relevant impact on the health-economic results. Rather, inclusion of capital costs would increase the treatment cost difference between the well-equipped and costly ED and the less specialised H-GP-unit. Finally, our study is observational and confounding cannot be excluded. An experimental design in one emergency care centre, however, is hardly possible and prone to contamination effects.

\section{Other health-economic data}

Studies that have assessed the health-economic consequences of changing the patient flow in hospital emergency services are scarce or results are difficult to compare for methodological reasons. For example, a Dutch study assessed the economic impact of a hospital integrated GP-cooperative but applied a capitation approach for cost analysis. ${ }^{19}$

The relationship between healthcare costs and quality of care is under debate and evidence is inconsistent. ${ }^{20} 21$ Some authors argue, that improvements in quality of care are associated with raised costs (eg, due to costly medical innovations). ${ }^{22}$ This may be different for interventions that focus on process of care. From the health-economic point of view, our new service model shows 'dominance' over the traditional model and holds promise as a business case for quality improvement ${ }^{23}$ : Service quality improved and costs for treatment of outpatient emergency contacts decreased simultaneously.

\section{Significance of findings and implications for decision makers}

Our findings are of significance for hospital decision makers outside Switzerland also. A quality improvement project with implementation of a fast track in emergency services holds several collateral benefits. ${ }^{4}$ For example, networking with community health services via integrated GPs as well as know-how transfer between hospital and community health professionals can be promoted. Furthermore, there is evidence that reduced waiting times can have positive influence on safety issues in the high-risk field of emergency medicine. ${ }^{5}$

On the other hand, initial intervention costs (eg, staff time and possibly new premises) have to be taken into account for hospital management. Furthermore, in fee-for-service outpatient systems, such as in Germany or Switzerland, fewer services per patient in the fast track (eg, less diagnostic testing) may result in lower revenues from payers. From the hospital perspective, this may lead to conflicting interests. ${ }^{23}$ Economic incentives should be in place so that the viewpoint of the healthcare system as a whole is considered, that is, treatment of emergency patients with suitable services at reasonable costs. Also from the public or third party payer perspective it is attractive to pass on patients with less severe problems to a H-GP-unit or similar services. Thus, scarce resources can be targeted to other areas.

While internal validity of our data is presumed to be high, applicability of our findings to other hospitals or healthcare settings (external validity) may be less straightforward. Our intervention, however, followed accepted steps for sustainable change and thus might be replicable for other providers, too. ${ }^{4}$ Similar activities have been launched in other Swiss hospitals, ${ }^{24}{ }^{25}$ but economic effects have not yet been evaluated as thoroughly as in our project.

As any organisational intervention is system dependent, a clear statement of change from the hospital management is necessary. Furthermore, the environment of the hospital has to be taken into account. At the start of our project, some emergency-care stakeholders in the community showed resistance to the new model. Transparent communication was essential to successfully deal with this initial resistance.

\section{Implications for health services research}

Health economic data are important to thoroughly evaluate quality improvement projects in a comprehensive approach. We applied this approach in Zurich for a hospital ED service, ${ }^{8}{ }^{10}$ as well as for the GP out-of-hours emergency service, ${ }^{11}{ }^{12}$ which are the main service options for emergency patients. Our cross-services-evaluation clearly showed the interdependency of both service options due to divergent patient demands and health problems. ${ }^{10}$ Simultaneous assessment of health-economic data also resulted in increased transparency of costs for the community. These data can be useful for local or national health policy decisions. By simultaneous assessment of service provision and health-economic data health services research can contribute to further optimising emergency services. 


\section{CONCLUSIONS}

From the health-economic point of view, our new service model shows 'dominance' over the old model: While quality of service provision improved, treatment costs sustainably decreased against the secular trend of increase. This can stimulate similar activities in other suitable emergency-care settings.

Acknowledgements We would like to thank Peter Imbach, MD, for his helpful comments and coordination of the H-GP. Our thanks go to the staff of the ED and H-GP at the City Hospital Waid for their very thorough data collection. We would like to express our gratitude towards 'Verein Outcome' for scanning and processing the data. Thanks also to Paul Kelly for English proofreading of the manuscript. The following people are members of the scientific board of the ongoing study which evaluates the implementation of the H-GP at the City Hospital Waid: Holger Auerbach, Urs Brügger, Klaus Eichler, Sascha Hess, Isabelle Rüthemann (Institute of Health Economics, Zurich University of Applied Sciences, Winterthur); Peter Rüesch (Centre for Health Sciences, Department for Health Professions, Zurich University of Applied Sciences, Winterthur); Thomas Rosemann, Oliver Senn, Marco Zoller, (Institute of General Practice and Health Services Research, University of Zurich).

Contributors KE made substantial contributions to conception and design, coordination, and acquisition of data. He also performed the health economic analysis; participated in interpretation of data and drafted the manuscript. SH, CC $K B, P S, O S$, TR and UB made substantial contributions to conception and design, coordination, acquisition of data, or analysis and interpretation of data. All authors revised the draft manuscript critically for important content and read and approved the final version.

Funding The study was supported by a project fund of the Health Department of the City of Zurich, Switzerland. The funding source had no influence on study design; on the collection, analysis and interpretation of the data; on the writing of the manuscript; and on the decision to submit the manuscript for publication.

\section{Competing interests None.}

Ethics approval Approval of the study was given by the local ethics committee (reference Nr. 26/09).

Provenance and peer review Not commissioned; externally peer reviewed.

Open Access This is an Open Access article distributed in accordance with the Creative Commons Attribution Non Commercial (CC BY-NC 3.0) license, which permits others to distribute, remix, adapt, build upon this work non-commercially, and license their derivative works on different terms, provided the original work is properly cited and the use is non-commercial. See: http://creativecommons.org/ licenses/by-nc/3.0/

\section{REFERENCES}

1 Guo B, Harstall C. Strategies to reduce emergency department overcrowding. HTA Report \#38. Edmonton, Alberta, Canada: Alberta Heritage Foundation for Medical Research, 2006.

2 Huibers $L$, Giesen $P$, Wensing $M$, et al. Out-of-hours care in western countries: assessment of different organizational models. BMC Health Serv Res 2009;9:105

3 Bindman $A B$, Forrest $C B$, Britt $H$, et al. Diagnostic scope of and exposure to primary care physicians in Australia, New Zealand, and the United States: cross sectional analysis of results from three national surveys. BMJ 2007;334:1261.

4 Swedish Council on Health Technology Assessment. Triage and flow process management in emergency departments. A systematic review. In SBU Report. Stockholm, Sweden, 2010
5 Guttmann A, Schull MJ, Vermeulen MJ, et al. Association between waiting times and short term mortality and hospital admission after departure from emergency department: population based cohort study from Ontario, Canada. BMJ 2011;342: d2983.

6 Leibowitz R, Day S, Dunt D. A systematic review of the effect of different models of after-hours primary medical care services on clinical outcome, medical workload, and patient and GP satisfaction. Fam Pract 2003;20:311-17.

7 Drummond $\mathrm{M}$, Sculpher $\mathrm{M}$, Torrance $\mathrm{G}$, et al. Methods for the economic evaluation of health care programmes. Vol. 3rd edn. Oxford: Oxford University Press, 2005.

8 Senn 0, Eichler K. Notfallpraxis Stadtspital Waid. Ein Projekt im Gesundheitsnetz 2025. Projektabschlussbericht der wissenschaftlichen Evaluation. Zurich, Winterthur: Institute of Primary Care and Health Services Research, University of Zurich; Winterthur Institute of Health Economics, Zurich University of Applied Sciences, 2012.

9 Hess $S$, Sidler $P$, Eichler $K$, et al. Implementing a primary care center at an emergency departement and its impact on staff satisfaction. In Swiss Public Health Conference. Lausanne, 2012.

10 Chmiel C, Huber CA, Rosemann T, et al. Walk-ins seeking treatment at an emergency department or general practitioner out-of-hours service: a cross-sectional comparison. BMC Health Serv Res 2011;11:94.

11 Eichler K, Imhof D, Moshinsky CC, et al. The provision of out-of-hours care and associated costs in an urban area of Switzerland: a cost description study. BMC Fam Pract 2010;11:99.

12 Huber $C$, Rosemann T, Zoller $\mathrm{M}$, et al. Out-of-hours demand in primary care: frequency, mode of contact and reasons for encounter in Switzerland. J Eval Clin Pract 2011;17:174-9.

13 Cochrane Effective Practice and Organisation of Care Group. EPOC Data Collection Checklist, 2013.

14 Elshove-Bolk J, Mencl F, van Rijswijck BT, et al. Validation of the emergency severity index (ESI) in self-referred patients in a European emergency department. Emerg Med J 2007;24:170-4.

15 WONCA. International classification of primary care. New York: Oxford University Press, 2005.

16 Gesundheitsdirektion Kanton Zürich: Handbuch Prisma. Wegleitung zur Erhebung des Patientenrecord in der Somatik. Zürich: Gesundheitsdirektion Kanton Zürich, 2012:46-7.

17 Altman D, Machin D, Bryant T, et al. eds. Statistics with confidence. Bristol: BMJ Books, 2001.

18 Barber JA, Thompson SG. Analysis of cost data in randomized trials: an application of the non-parametric bootstrap. Stat Med 2000;19:3219-36.

19 van Uden CJ, Ament AJ, Voss GB, et al. Out-of-hours primary care. Implications of organisation on costs. BMC Fam Pract 2006;7:29.

20 Hussey PS, Wertheimer $S$, Mehrotra A. The association between health care quality and cost: a systematic review. Ann Intern Med 2013;158:27-34.

21 Jarlier A, Charvet-Protat S. Can improving quality decrease hospital costs? Int J Qual Health Care 2000;12:125-31.

22 Rauh SS, Wadsworth EB, Weeks WB, et al. The savings illusion-why clinical quality improvement fails to deliver bottom-line results. N Engl J Med 2011;365:e48.

23 Leatherman $S$, Berwick $D$, lles $D$, et al. The business case for quality: case studies and an analysis. Health Aff (Millwood) 2003;22:17-30.

24 Guntensperger U, Pinzello-Hurlimann R, Martina B, et al. Primary care emergency services utilization in German-speaking Switzerland: a population-based cross-sectional study. Swiss Med Wkly 2010;140:w13111.

25 Horn R, Sibalic V, Osterwalder JJ. Hausarzt in der Notfallpraxis eines Zentrumsspitals. Schweizerische Ärztezeitung 2010;91:2012-14. 